\title{
Impedance monitoring of fuel cell stacks
}

\author{
Pawel Slepski • Ewa Janicka • Kazimierz Darowicki • \\ Boguslaw Pierozynski
}

Received: 25 August 2014 /Revised: 5 November 2014 / Accepted: 7 November 2014 / Published online: 25 November 2014

(C) The Author(s) 2014. This article is published with open access at Springerlink.com

\begin{abstract}
This paper presents an innovative, electrochemical impedance method for monitoring of electrochemical behaviour of a multi-cell, direct methanol fuel cell (DMFC) device. This method not only provides classical voltage changes at successive cells but also allows their detailed impedance behaviour to be presented. Impedance characteristics of individual cells within a fuel cell stack (depending on actual operating conditions) are obtained via numerous electrochemical tasks, including simultaneous determination of each cell's impedances, performance optimization of the fuel cell stack and effective detection of faulty cells within the stack. The above concerns in situ conditions. The effectiveness of the present method was studied here on a seven-cell, commercially made DMFC stack. In order to effectively detect faulty cells, selected experiments were carried out with insufficient amount of oxygen supplied to a cathode input (ca. $25 \%$ of optimal oxidant dose was used).
\end{abstract}

Keywords Electrochemical impedance spectroscopy $\cdot$ Fuel cell diagnostics · Direct methanol fuel cell (DMFC) stack

P. Slepski $\cdot$ E. Janicka $(\bowtie) \cdot K$. Darowicki

Department of Electrochemistry, Corrosion and Materials

Engineering, Gdansk University of Technology, 11/12 Narutowicza

Street, 80-233 Gdansk, Poland

e-mail: ewa.janicka@pg.gda.pl

B. Pierozynski

Department of Chemistry, University of Warmia and Mazury in

Olsztyn, Plac Lodzki 4, 10-957 Olsztyn, Poland

\section{Introduction}

Fuel cells (FCs) become widely recognized as attractive devices for direct generation of electrical energy from the combustion of various chemical substances. The most important for portable power applications are low temperature fuel cells, structured around a proton-exchange membrane assembly and typically fuelled with simple aliphatic alcohols, e.g. methanol or ethanol. In this respect, fuel cells could be considered significantly advantageous over current lithium-ion batteries, which represent limited capacity and somewhat deficient charge/discharge characteristic systems [1-3]. As single cells cannot generate sufficient power to run any simple electric device, they are typically linked in series or in parallel combinations to make fuel cell stacks. Hence, each cell has a direct impact on the operation of an entire FC assembly.

The most popular method for the monitoring of electrochemical behaviour of fuel cell stacks is a direct-current (dc) method, which is based on the voltage determination for the fuel cell stack $[4,5]$. In addition, there have also been attempts to employ alternate-current (ac) techniques, which could yield important and detailed information from every single measurement [6-13]. Unfortunately, application of such ac methods to monitor the FC characteristics is still somewhat limited, due to the complexity of employed electrochemical equipment [11, 12].

Recently, a new dynamic electrochemical impedance spectroscopy (DEIS) technique has successfully been introduced for in situ monitoring of single fuel cells [14-16]. This method, due to its simplicity, could quite easily be employed to monitor the electrochemical behaviour of fuel cell stacks. Here, authors of this work describe a practical application for the DEIS method to monitor the electrochemical characteristics of an entire fuel cell stack, as well as its independent constituents. 


\section{Material and methods}

Presented here, electrochemical impedance method for the monitoring of the electrochemical behaviour of a direct methanol fuel cell stack closely resembles that of the voltage type, i.e. both techniques involve voltage recording for consecutive cells of the stack being under load. A key difference between these methods lies in the fact that for the former technique (contrary to the latter one), a current load also contains an ac component that is based on suitably selected sinusoidal signals. Electrochemical processes that occur within single cells trigger the corresponding voltage changes for both the dc and ac components. Also, according to the Nyquist principle, appropriate detection of the ac component requires that the voltage signals from individual cells be registered with the speed that is at least double that of the highest component of the excitation frequency [17].

In fact, continuous recording of numerous voltage signals could trigger excessive load on the measurement system. Therefore, the authors of this work suggest that the Goertzel transformation be employed. Its operation is analogous to that of the discrete Fourier transform (DFT), where only a single frequency line (not a complete spectrum) is analysed in order to detect a complex value for a given frequency. Here, we have only analysed frequencies based on multi-sinusoidal excitation. This approach allows to radically limit the required number of calculations. In contrast to the DFT approach, the Goertzel transformation allows to continuously analyse the signal, thus enabling online data (e.g. impedance) presentation. Detailed information on implementation of this method in order to obtain the impedance characteristics is given in work by Lentka and Niedostatkiewicz [18].

The laboratory-examined DMFC stack (see Fig. 1) was supplied by Quintech (Germany) and consisted of seven individual cells with an active, geometrical surface area of $50 \mathrm{~cm}^{2}$ each. The role of electrolyte was played by a membrane, commercially known as Nafion 117. Anodes were Pt-Ru catalyst-based ( $4 \mathrm{mg} \mathrm{cm}^{-2}$ ), deposited on carbon support, whereas $4 \mathrm{mg} \mathrm{cm}^{-2}$ of $\mathrm{Pt}$ (also on the carbon support) accounted for an active cathode material. An aqueous solution of $0.5 \mathrm{M} \mathrm{CH}_{3} \mathrm{OH}$ was supplied to the fuel cell by a peristaltic pump (Gilson Minipuls 3), at a rate of $10 \mathrm{~cm}^{3} \mathrm{~min}^{-1}$. Air was used as an oxidant, typically at a rate of $1 \mathrm{dm}^{3} \mathrm{~min}^{-1}$. At the increased load of the FC stack, appropriate amounts of the oxidizer and fuel were selected, so that the stack would be operated with shortage in the supply of oxygen.

For the impedance measurements, a multi-sinusoidal current excitation at a frequency range, $4.5 \mathrm{kHz}-30 \mathrm{mHz}$ (or $170 \mathrm{mHz}$ ), generated by a PXI-4461 card, was applied. Both amplitude and phase shift of the components were appropriately selected so that the voltage amplitude of the ac response did not exceed $25 \mathrm{mV}$ pp (peak to peak) during the measurement. The signal was input into the Autolab $302 \mathrm{~N}$ unit, where

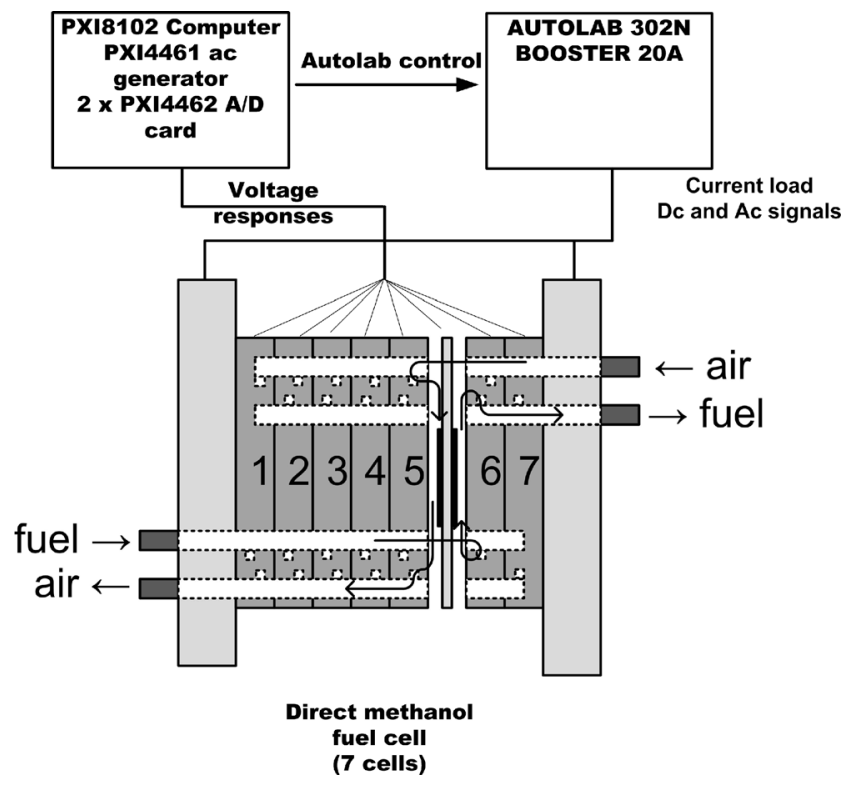

Fig. 1 Schematic diagram of a laboratory-tested DMFC stack

it was supplemented with the dc current signal, and then applied to the cell under examination. During all measurements, separate PXI-4462 cards were used to record voltage and current values. System control and analysis of online signals were performed through the software application developed for LabView environment. Other details of this method were discussed by Slepski et al. elsewhere [17].

\section{Results and discussion}

Electrochemical performance of a fuel cell is typically realized during a galvanodynamic measurement, during which the cell's voltage is recorded upon linearly increasing current

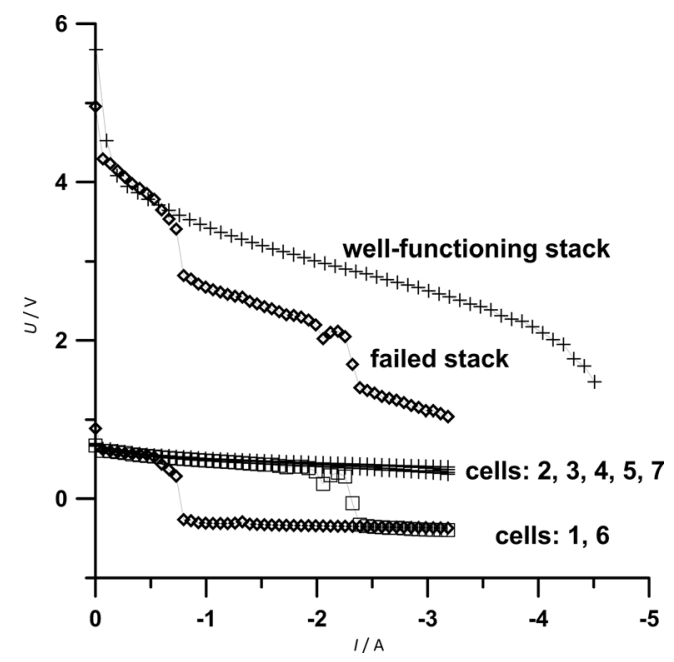

Fig. 2 Recorded voltage drop for a DMFC stack, well-functioning stack (plus sign) and failed stack (diamond). Individual cells, well-functioning cells (plus sign), first cell (square) and sixth cell (diamond), in function of increasing current load 
Table 1 Stoichiometric coefficients for the reagents in function of the stack's current load

\begin{tabular}{lll}
\hline $\begin{array}{l}\text { Stack's load } \\
\left(\mathrm{mA} \mathrm{cm}{ }^{-2}\right)\end{array}$ & $\begin{array}{l}\text { Stoichiometric coefficient for } \\
3 \mathrm{wt} \% \text { methanol solution }\end{array}$ & $\begin{array}{l}\text { Stoichiometric } \\
\text { coefficient for air }\end{array}$ \\
\hline 20 & 12.92 & 7.69 \\
40 & 6.46 & 3.84 \\
60 & 4.31 & 2.56 \\
80 & 3.23 & 1.92 \\
\hline
\end{tabular}

load. Figure 2 below shows such relationship obtained for the tested FC stack, for the case of nearly equivalent amounts of fuel and oxidant, and with deficiency of the oxidant. The demand for fuel and oxygen depends on the amount of electricity produced by the fuel cell. Hence, for fixed flow rates of the reagents ( $3 \mathrm{wt} \% \mathrm{CH}_{3} \mathrm{OH}+$ air), stoichiometric coefficients significantly changed upon an increase of the FC stack's load. Table 1 below presents stoichiometric coefficients for the reagents (being under constant flow rates and with the deficiency of the oxidant) in function of the stack's load.

Hence, initially increasing load to the FC stack resulted in similar voltage changes for both studied oxidant flows. However, a dramatic voltage drop (from ca. 3.5 to $2.8 \mathrm{~V}$ ) was recorded at the load of $0.8 \mathrm{~A}$ for the case of the reduced oxidant flow ( $25 \%$ of the optimum value). Another sharp potential drop could clearly be observed at the load of ca. 2.4 A (see
Fig. 2 again). This phenomenon will now be discussed based on the behaviour of individual constituents of the FC stack. It can be seen in Fig. 2 that working conditions inside the cells denoted as no. 1 and no. 6 significantly changed during the experiments, as compared to those of other cells. As a consequence, the cell no. 1 and no. 6 reversed their polarities, and therefore efficiency of the FC stack considerably dropped.

Additional information could be derived from the recorded changes of the impedance behaviour for the fuel cell stack in Fig. 3a. Hence, individual spectra in the Nyquist impedance plots show the existence of two time constants that vary in function of increasing load. Thus, small fluctuations that could be observed in Fig. 3a under the loads of 0.8 and 2.4 A are associated with the corresponding failures inside the cell no. 1 and no. 6 . Figure $3 \mathrm{~b}$ presents the impedance behaviour of cell no. 3, which represents all properly functioning cells. The recorded characteristics are continuous and seem quite analogous to that presented in the impedance diagram of Fig. 3a. Significantly different behaviour was observed for the cells with reversed polarity. Thus, for the cell no. 1, individual impedance spectra exhibited two time constants, until the FC load reached $2.4 \mathrm{~A}\left(0.05 \mathrm{~A} \mathrm{~cm}^{-2}\right)$. Then, the shape of the impedance spectra changed. Interestingly, for the cell no. 6 , relevant changes were already observed at the current of $0.8 \mathrm{~A}$ (ca. $0.02 \mathrm{~A} \mathrm{~cm}^{-2}$ ). The presence of two time constants is typical to the impedance spectra describing the behaviour of
Fig. 3 a Impedance diagram for a DMFC stack under variable current load. b Impedance diagram for third cell of a DMFC stack under variable current load. c Impedance diagram for first cell of a DMFC stack under variable current load. d Impedance diagram for sixth cell of a DMFC stack under variable current load
A)

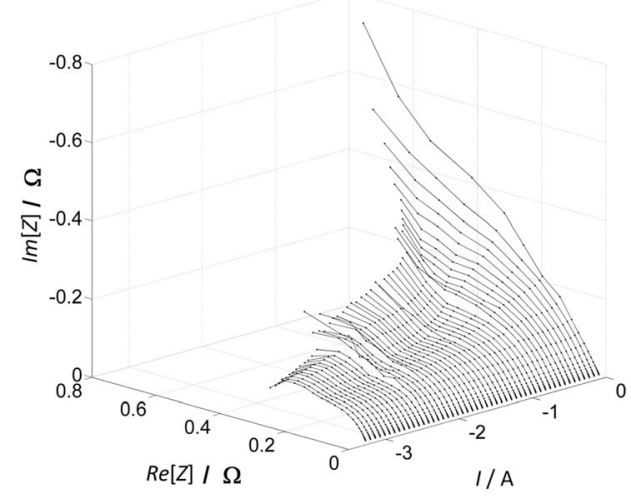

C)

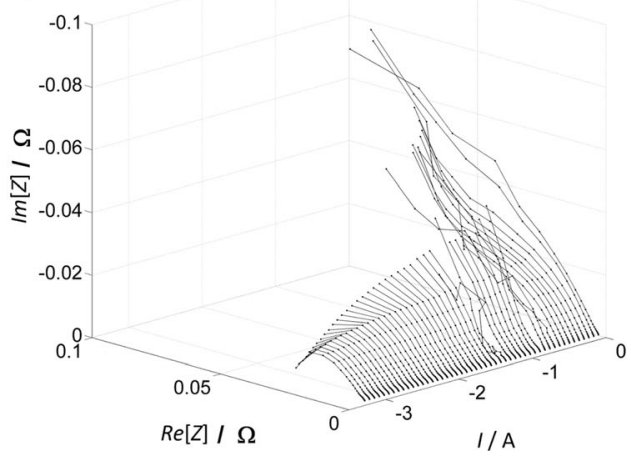

B)

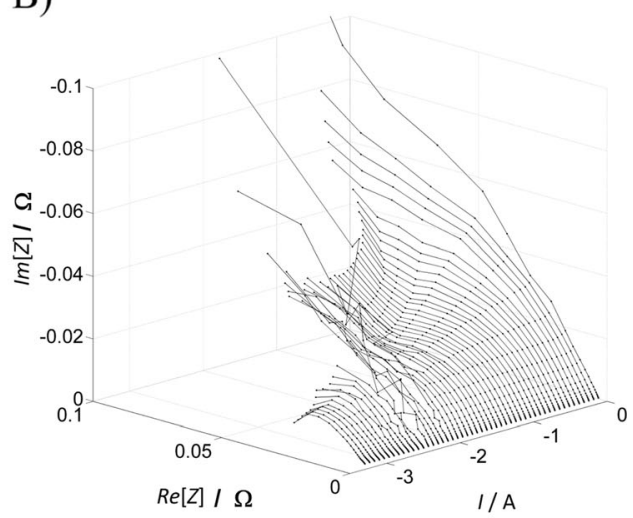

D)

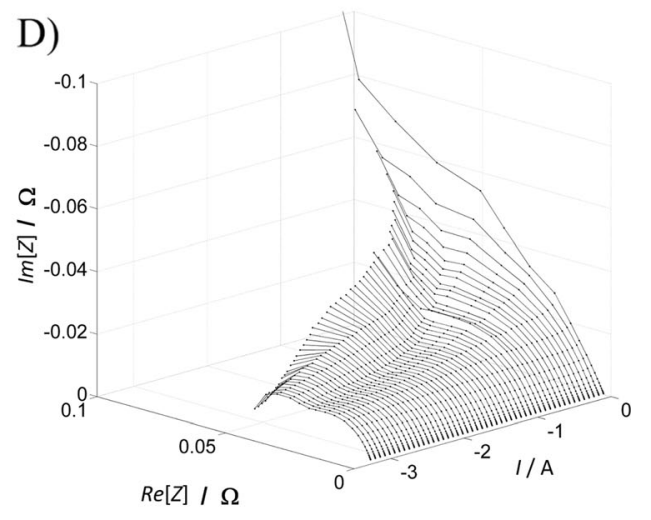




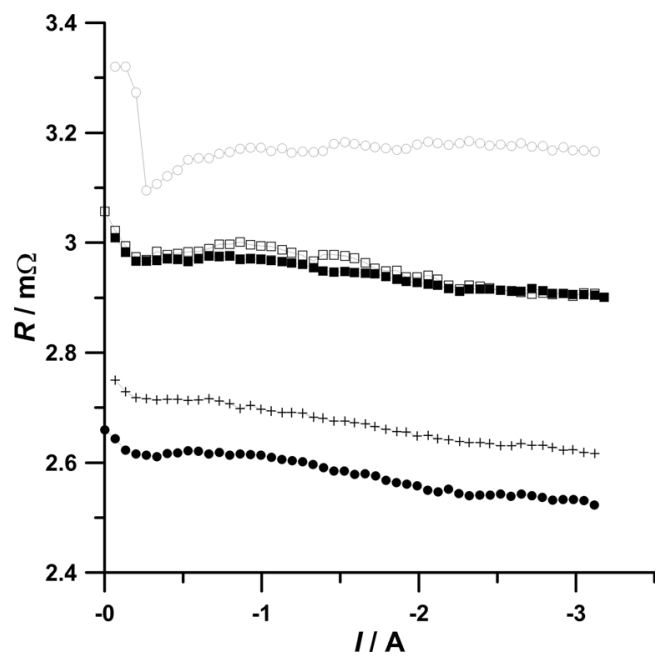

Fig. 4 Changes of $R^{\mathrm{ST}}$ parameter in function of variable current load for properly functioning cells of a DMFC stack: second cell (black circle), third cell (black square), fourth cell (plus sign), fifth cell (white square) and seventh cell (white circle)

an entire stack. Thus, their analysis allows no conclusions to be made about specific changes undergoing within individual electrodes. It is well-known that upon electricity generation by a DMFC device, methanol becomes oxidized at anode to form carbon dioxide, whereas oxygen gets reduced at a cathode side. However, in the case of insufficient amount of oxygen delivered to the cathode surface, the fuel cell is practically unable to generate electric current. Simultaneously, proton reduction becomes a primary reaction to proceed on the cathode surface:

$2 \mathrm{H}^{+}+2 \mathrm{e}^{-} \rightarrow \mathrm{H}_{2}$

In addition, for the cells with reversed polarity, the cathodic reaction gets very fast, and the impedance diagrams shown in

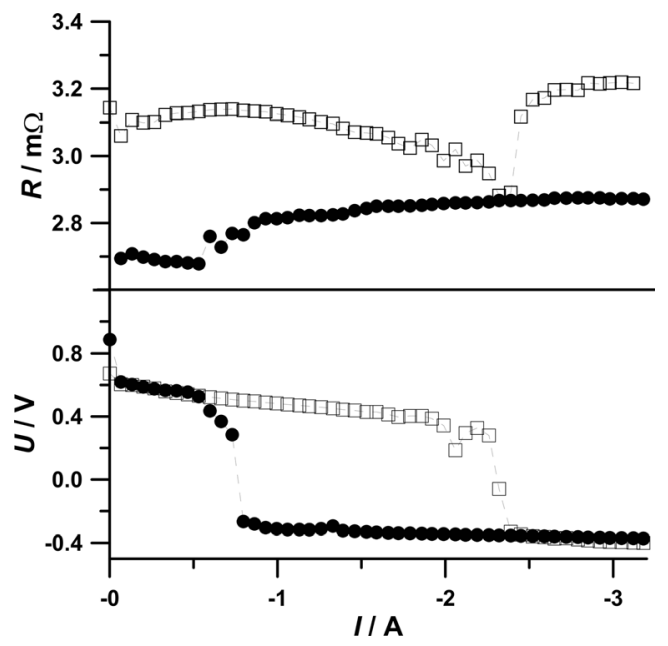

Fig. 5 Changes of $R^{\mathrm{ST}}$ and voltage drop parameters in function of variable current load for failed cells of a DMFC stack: first cell (square) and sixth cell (circle)

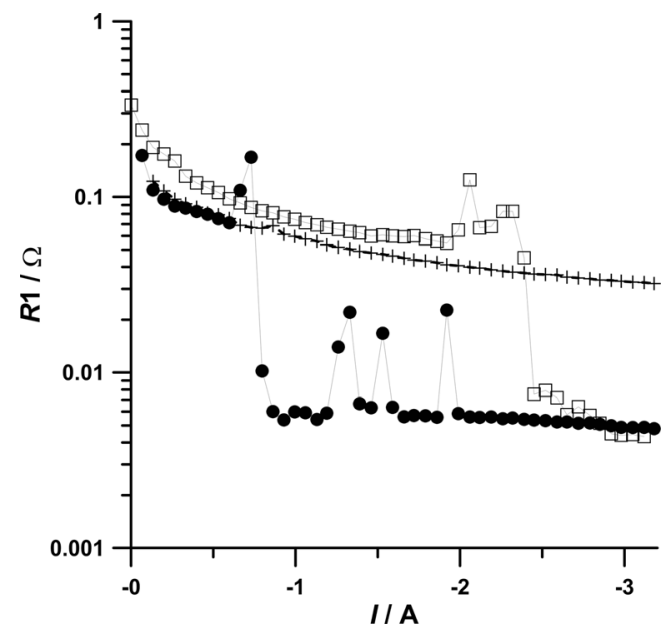

Fig. 6 Changes of $R_{1}$ parameter in function of variable current load for a DMFC stack: first cell (square), third cell (plus sign) and sixth cell (circle)

Fig. $3 \mathrm{c}, \mathrm{d}$ changed their shape just to mimic that of the anode part.

The resulting instantaneous value of the impedance makes the sum of individual impedance components from anodic and cathodic regions of each cell. Physical interpretation of the recorded two time constants by means of physical/chemical methods is practically impossible. In contrast, the resistance measured between the p. [0.0] and the beginning of the first time constant in the Nyquist plot could be attributed to the resistance of the membrane $[19,20]$, which governs the transport of protons between the electrodes (anode and cathode). Figures 4 and 5 below illustrate changes of the membrane resistance in function of the applied load for "sound" and failed FC stack constituents, respectively.

Thus, for a well-functioning cell, the membrane resistance initially exhibited a rapid decrease followed then by a linear, monotonic drop of the measured parameter. This behaviour is most likely related to activation control for an initial phase of electrode reaction, where the load increase induces extensive

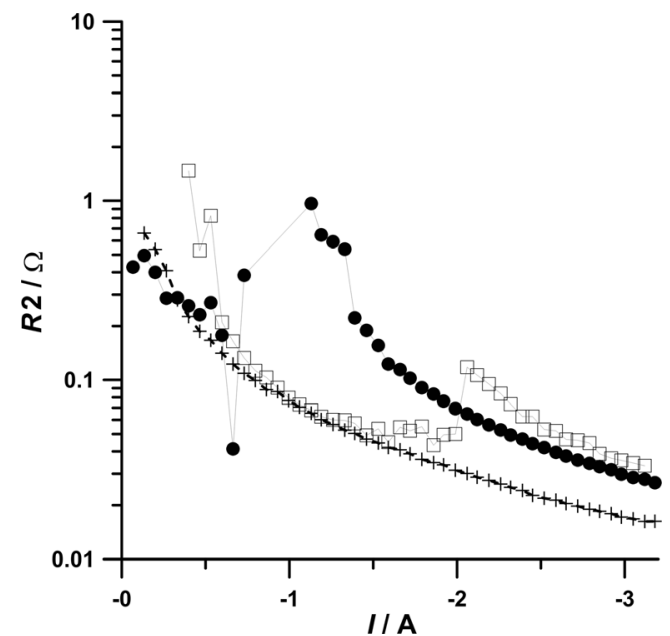

Fig. 7 Changes of $R_{2}$ parameter in function of variable current low for a DMFC stack: first cell (square), third cell (plus sign) and sixth cell (circle) 
potential shifts along with improved membrane hydration and typical behaviour for the stack under operational conditions. Then, there is a mixed type of reaction control, and further voltage changes are rather monotonic. Also, based on the comparison of $R_{1}$ and $R_{2}$ parameter values for the cell no. 3, one can notice that the second time constant is to a higher degree dependent on the generated current level by the FC stack.

On the contrary, for the cells that suffered damage (cell nos. 1 and 6), there is a strict correlation between the drop of voltage and increase of the resistance parameter. In fact, when the cell stops properly functioning, the membrane resistance rises to or even beyond its initial value. Moreover, an increase of series resistance (strongly dependent on the extent of membrane hydration) becomes evident. The latter effect is related to the fact that water is no longer a product of the cathodic reaction; it became replaced by $\mathrm{H}_{2}$.

As mentioned earlier, the recorded impedance spectra exhibited two time constants with rather ambiguous physical meanings. However, they could conveniently be used to detect possible malfunctions within the fuel cell stack (the corresponding resistances of the first and the second time constant in function of the load for the selected cells are shown in Figs. 6 and 7, respectively). Hence, for the defected cells, the $R_{1}$ and $R_{2}$ parameter values are strongly dependent on the event of polarization reversal. In the case of the first time constant, it means its dramatic reduction, a consequence of insignificant parallel impedance for the cathodic reaction after the polarization reversal, as compared to the reaction that occurs under regular operational conditions. On the other hand, the second time constant starts increasing after the cell's breakdown.

As in the case of the membrane, a failure of the cell involves an abrupt change of the resistance, namely, reduction of the first and increase of the second time constant, correspondingly. On the other hand, for properly functioning FC stack, all resistance changes are monotonic/continuous.

\section{Conclusions}

This work describes a simple but comprehensive method for the monitoring of electrochemical characteristics of fuel cell stacks. The method enables to derive and present the impedance changes for multi-cell stacks (along with detailed analysis of individual cells), upon variation of operational conditions within a fuel cell, e.g. increasing current load. Finally, it allows in-line, indirect detection of working efficiency drop for examined fuel cell stacks.

Acknowledgments The authors would like to acknowledge the financial support from the Ministry of Science and Higher Education of the Republic of Poland, under Grant 2012/05/N/ST8/02918.

Open Access This article is distributed under the terms of the Creative Commons Attribution License which permits any use, distribution, and reproduction in any medium, provided the original author(s) and the source are credited.

\section{References}

1. Antolini E (2007) J Power Sources 170:1-12

2. Suo Y, Hsing IM (2011) J Power Sources 196:7945-7950

3. Roy PS, Bagchi J, Bhattacharya SK (2012) Catal Sci Technol 2: 2302-2310

4. Chu D, Jiang R (2006) Electrochim Acta 51:5829-5835

5. Icardi UA, Specchia S, Fontana GJR, Saracco G, Specchia V (2008) J Power Sources 176:460-467

6. Li X, Faghri A (2012) Int J Hydrogen Energ 37:14549-14556

7. Yan X, Hou M, Sun L, Liang D, Shenb Q, Xua H, Ming P, Yi B (2007) Int J Hydrogen Energ 32:4358-4364

8. Springer TE, Zawodzinski TA, Wilson MS, Gottesfeld S (1996) J Electrochem Soc 143:587-599

9. Yuan X, Sun JC, Wang H, Zhang J (2006) J Power Sources 161:929937

10. Zhu WH, Payne RU, Tatarchuk BJ (2007) J Power Sources 168:211217

11. Hakenjos A, Zobel M, Clausnitzer J, Hebling C (2006) J Power Sources 154:360-363

12. Diard JP, Glandut N, Gorrec BL, Montella C (2004) J Electrochem Soc 151:A2193-A2197

13. Buttin D, Dupont M, Straumann M, Gille R, Dubois JC, Ornelas R, Fleba GP, Ramunni E, Antonucci V, Arico V, Creti P, Modica E, Pham-Thi M, Ganne JP (2001) J Appl Electrochem 31:275-279

14. Janicka E (2013) Przem Chem 92:232-234

15. Slepski P, Darowicki K, Janicka E, Lentka G (2012) J Solid State Electr 16:3539-3549

16. Darowicki K, Janicka E, Slepski P (2012) Int J Electrochem Sci 7: 1209012097

17. Slepski P, Darowicki K, Andrearczyk K (2009) J Electroanal Chem 633:121-126

18. Lentka G, Niedostatkiewicz G (2004) Proc. 13th Int. Symp. on Meas. for Research and Industry Applications IMEKO TC-4 Athens 1:110 115

19. Seo SJ, Woo JJ, Yun SH, Lee HJ, Park JS, Xu T, Yang TH, Moon SH (2010) Phys Chem Chem Phys 12:15291-15300

20. Albery WJ, Mount AR (1994) J Chem Soc Faraday Trans 90:11151119 